\title{
Mobile Customer Demand Discrimination Modeling in Enterprise Information Systems
}

\author{
Yajing Si, Jiayin Qi, Huaying Shu, and Hua $\mathrm{Ai}$ \\ Economics and Managment School, Beijing University of Posts and \\ Telecommunications, $10 \mathrm{Xi}$ Tu Cheng Road, Haidian District, Beijing, \\ China, 100876 \\ mail2syj@126.com \\ ssfajy@263.net, \\ shuhy@bupt.edu.cn, \\ aidahere@tom.com \\ WWW home page: http://www.sem.bupt.cn
}

\begin{abstract}
In the highly competitive environment, the real-time and dynamic customer demand analysis technology is required by the enterprise information systems in order to respond to the customer demand efficiently and automatically. Based on the background of mobile industry, this paper makes a mobile customer demand analysis model and proposes ways to capture customer demand knowledge. Firstly, a contour model of customer value layers is gotten by investigation and specific interview; secondly, the significant attributes of customer value layers are screened out; finally, a customer demand discrimination model is built while making the customer demand objective layer as the output of the model and making customer demand attribute layer as the input of the model. Well-formed model could judge the classification of customer demand objectives dynamically from their demand attributes. This model is used in analysis of mobile customer samples.
\end{abstract}

\section{Introduction}

In the highly competitive environment, the mobile operators must be able to adjust their service processes to respond to market shifts and various customer needs efficiently and automatically. Therefore, the real-time and dynamic customer demand analysis technology is required for the enterprise information systems. Influenced by the aim, environment and individual preference, the different customer group leads to the difference of customer demand [1] [2]. Previous studies mainly focus on these subjects: firstly, predicting customer preferences and repeat-purchase

Please use the following format when citing this chapter:

Si, Y., Qi, J., Shu, H., Ai, H., 2006, in International Federation for Information Processing, Volume 205, Rescarch and Practical Issues of Enterprise Information Systems, eds. Tjoa, A.M., Xu, L., Chaudhry, S., (Boston:Springer), pp.583-588. 
patterns through consume history analysis [3]; secondly, analyzing the antecedents and consequences of consume behavior and customer loyalty [4] [5]; thirdly, classifying customers by using clustering analysis [6]. It's a bit subjective with such a low intelligence level and large manual work. Woodruff, Butz and Goodstein proposed the CVD (Customer Value Determination) and built the correlative relationships among the customer demand attribute layer, the consequence layer and the objective layer [7]. However this research did not present technical tools to implement the CVD knowledge capture. Based on the background of mobile industry, this paper makes mobile customer demand analysis model and proposes ways to capture customer demand knowledge. Firstly, a contour model of customer value layer is gotten by investigation; secondly, the significant attributes of customer value layers are screened out; finally, a customer demand discrimination and analysis model is built. Well-formed model could judge the classification of customer demand objectives dynamically from their choices on demand attribute layer. We use this method to analyze the samples of 122 mobile telecommunication customers.

\section{Framework for Customer Demand Discrimination}

The supporting framework for the process of mobile costumer demand analysis is presented in Fig.1. The subsequent sections of this paper will explore it in detail.

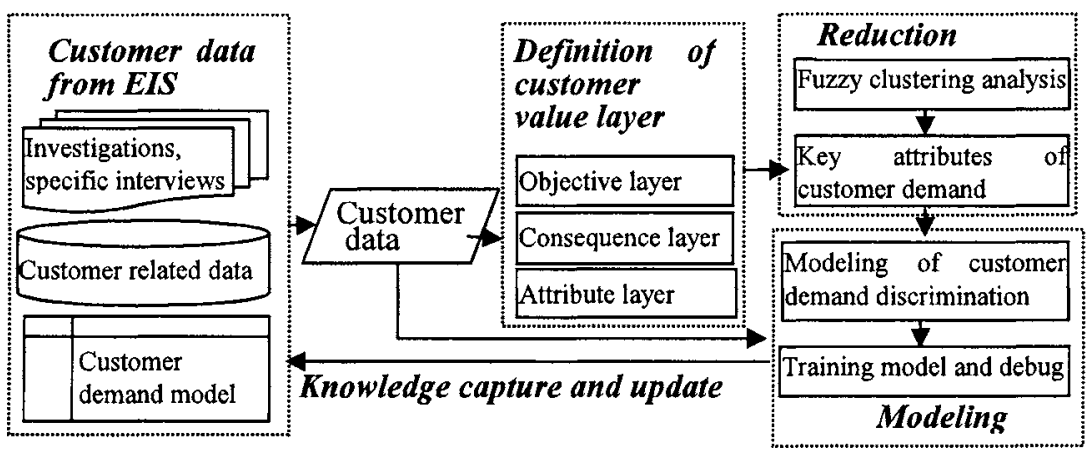

Fig. 1. Framework for customer demand discrimination 


\section{Mobile Customer Demand Discrimination Modeling and the Knowledge Capture}

\subsection{Contour Model of Mobile Customer Value Hierarchy}

Woodruff advanced the CVD indicating that from the bottom of customer value hierarchy, customers firstly consider the attributes and availabilities of products. At the second layer, customers begin to make expectation according to these attributes. At the top layer, customers form expectation about the realization of their aim. In this paper, the mobile customer value hierarchy consists of three layers. The objective layer means the ultimate motivations of customers engaging in mobile telecommunication services. The Consequence layer means the customer experience of mobile services. The Attribute layer means the usage of mobile services. Based on the mobile customer interview that made in $\mathrm{X}$ city, this paper constructs the mobile customer value hierarchy presented in Table 1. The factors of objective layer and attribute layer are defined as the variable $a_{i} \square \mathrm{i}=1,2 \ldots 29 \square \square$

Table 1. Mobile Customer Value Hierarchy

\begin{tabular}{|c|c|c|c|c|c|c|c|c|}
\hline \multirow{2}{*}{$\begin{array}{l}\text { Objectives } \\
\text { Consequen } \\
\text { ces }\end{array}$} & \multicolumn{2}{|l|}{$\begin{array}{l}\text { Communicative } \\
\text { Object }(226)\end{array}$} & \multicolumn{2}{|c|}{ Business Object(a27) } & \multicolumn{2}{|l|}{$\begin{array}{l}\text { Recreational } \\
\text { Object }(228)\end{array}$} & \multicolumn{2}{|c|}{ Informational Object(229) } \\
\hline & \multicolumn{2}{|l|}{$\begin{array}{l}\text { Convenient } \\
\text { communication, }\end{array}$} & \multicolumn{2}{|c|}{$\begin{array}{l}\text { High quality, knight } \\
\text { service, high standing }\end{array}$} & \multicolumn{2}{|c|}{$\begin{array}{l}\text { Fashion, pleasure, } \\
\text { selfhood, fun }\end{array}$} & \multicolumn{2}{|l|}{$\begin{array}{l}\text { Knowledge, in time, } \\
\text { information }\end{array}$} \\
\hline \multirow[t]{7}{*}{ Attributes } & short massage & al & U-net & a6 & Color ring back & a13 & News service & a 19 \\
\hline & service call & & Routine service & a7 & tone & & Weather info & $a_{20}$ \\
\hline & waiting call & $a 2$ & Ticket booking & 28 & mobile ring & a14 & Travel info & 21 \\
\hline & diversion & 23 & Uni-colour E & ag & mobile picture & ats & Finance info & $a 22$ \\
\hline & fittle secretary & a4 & E-bank & $a 10$ & E-game & a16 & Physical news & a23 \\
\hline & voice mail box & a5 & Stock exchange & a11 & chat & a17 & Entertainment info & 24 \\
\hline & & & Mobile purchase & a12 & mobile movie & a18 & U-map & $a 25$ \\
\hline
\end{tabular}

\subsection{Significant Attributes Analysis of Customer Value Hierarchy}

The significant attributes of customer value hierarchy mean the key attribute variables of the attribute layer which distinctly correlate with the objective layer. This step is mainly to decrease the data dimension in customer demand analysis.

\section{A. The Principles of Significant Attributes Analysis}

According to the rough set theory, data of the customer value objective layer and attribute layer can be defined as $S=(U, A, V, f)$. Here, $U=\left\{u_{1}, u_{2}, \ldots, u_{n}\right\}$ : The set of customers where $m$ is the total number of customers. $A=\left\{a_{1}, a_{2}, \ldots a_{m}\right\}$ : The set of variables of the objective layer and the attribute layer. $A=C \cup D$, where $C$ is the characteristics set of the attribute layer, and $D$ is the characteristics set of the objective layer. $\mathrm{V}$ is the set of the customer attribute parameters. The value of 
$f\left(u_{j}, a_{i}\right)$ indicates the value of $u_{j}$ about $a_{i}$. The significant attributes analysis is solved by fuzzy cluster. The process of the analysis is:

Step 1. Partition customer set A into D and C. Consider the numerical character of attribute $\mathrm{a}_{\mathrm{i}}$ in attributes set $\mathrm{C}$, and represent attribute $\mathrm{a}_{\mathrm{i}}$ as $a_{i j}(\mathrm{j}=1,2, \ldots, \mathrm{k})$. Here $\mathrm{k}$ is the number of incoordinate value of attribute $a_{i}$.

Step2. Calculate the fuzzy similarity matrix R. Here:

$$
r_{i j}=\sum_{k=1}^{m}\left(a_{i k} a_{j k}\right)^{2} / \sqrt{\left(\sum_{i=1}^{m} a_{i k}^{2}\right)\left(\sum_{k=1}^{m} a_{j k}^{2}\right)}
$$

Step3. Calculate the fuzzy transitive closure $t(R)$ of the fuzzy correlation matrix $R$. Use the cluster method to analyze $t(R)$ with intercept $\lambda$ and find out the significant attributes set.

\section{B. The Process of Data Analysis}

The investigation gave 150 pieces of questionnaire out to the mobile individual customers in X city. 122 effective sheets of questionnaire were retrieved. The rate of retrieving efficiency is $81.3 \%$. The questionnaire contains two parts, questions about the importance of the consume objects in the objective layer and questions about whether the customers have engaged the services of the attribute layer. In order to be less costly and easily applied, 50 questionnaires are chosen as the analysis samples. From total 25 products/services, 13 products/services were found that have distinct correlation with the customer demand objective. The results are presented in Table 2.

Table 2. Significant Attributes of Attribute Layer

\begin{tabular}{|l|l|l|l|}
\hline objective layer & $\lambda$ & attributes cluster & $\begin{array}{l}\text { Significant } \\
\text { attributes }\end{array}$ \\
\hline Communicative Object & 0.908 & $\{\mathrm{a} 1\}\{\mathrm{a} 2, \mathrm{a} 3, \mathrm{a} 4\}\{\mathrm{a} 5\}$ & $\mathrm{a} 1, \mathrm{a} 2, \mathrm{a} 3, \mathrm{a} 4$ \\
\hline Business Object & 0.999 & $\{\mathrm{a} 6, \mathrm{a} 9\},\{\mathrm{a} 7\},\{\mathrm{a} 8, \mathrm{a} 10, \mathrm{a} 11, \mathrm{a} 12\}$ & $\mathrm{a} 6, \mathrm{a} 7, \mathrm{a} 9$ \\
\hline Recreational Object & 0.997 & $\{\mathrm{a} 13, \mathrm{a} 14\}\{\mathrm{a} 15\},\{\mathrm{a} 16\}\{\mathrm{a} 17, \mathrm{a} 18\}$ & $\mathrm{a} 13, \mathrm{a} 14, \mathrm{a} 15, \mathrm{a} 16$ \\
\hline Informational Object & 0.95 & $\{\mathrm{a} 19\},\{\mathrm{a} 20\},\{\mathrm{a} 21, \mathrm{a} 22, \mathrm{a} 23, \mathrm{a} 24, \mathrm{a} 25\}$ & $\mathrm{a} 19, \mathrm{a} 20$ \\
\hline
\end{tabular}

\subsection{Mobile Customer Demand Discrimination Modeling}

We build customer demand discrimination model while making the customer demand objective layer as the output of the model and making significant attributes of the attribute layer as the input of the model. This paper uses 61 customers as the training samples set and others as the contrastive samples set. The model is trained by adopting BP-neural network method, and the best acceptable training result is achieved. The accurate percentage of forecast is $80.517 \%$. The weight matrix from input layer to hidden layer $\mathrm{W}$ is described as:

The weight matrix from input layer to hidden layer $r$ is expressed as:

\begin{tabular}{|c|c|c|c|c|c|c|c|c|c|c|c|c|}
\hline $\mid-0.904$ & 0.673 & -0.824 & 258 & -0.3 & -0.334 & 0.016 & 0.138 & -0.019 & 0.352 & -0.788 & 1.263 & 0.533 \\
\hline & & & - & & 1 & 18 & 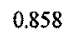 & 9 & 47 & & -0.415 & 0.07 \\
\hline-0.634 & 324 & 0.063 & 0.676 & 0.211 & -0.35 & -0.557 & -0.428 & -0.704 & 0.265 & -0.725 & 0.164 & 0.147 \\
\hline 0.507 & -0.224 & 0.441 & -0.201 & -0.027 & -0.205 & 0.156 & -0.579 & -0.478 & -0.792 & 0.036 & -1.022 & -1.48 \\
\hline 0.335 & .724 & -1.017 & 0.847 & -0.698 & -0.255 & 0.388 & -0.152 & -0.292 & 0.587 & -0.353 & -0.190 & 0.745 \\
\hline
\end{tabular}




$$
T=\left|\begin{array}{lccc}
0.918 & 0.393 & 0.921 & 0.973 \\
0.145 & -1.252 & 0.363 & -0.459 \\
0.852 & 0.724 & -0.424 & 0.509 \\
0.976 & -0.195 & -1.577 & -0.247 \\
0.992 & -0.537 & -0.395 & 1.527
\end{array}\right|
$$

\subsection{Customer Demand Knowledge Capture}

Well-formed model could judge the classification of customer demand objectives dynamically from their demand attributes. 2 customers are randomly selected from samples and the comparison between the analytical conclusions and the actual demands is presented in Table 3. For getting obvious conclusion, we assume 3 as the dividing line. It can be indicated that the model can discriminate the customer demand with high accurate percentage. Furthermore, the model can indicate a measurable conclusion based on customer motivation that has the advantage of high stability and reliability.

Table 3. Comparison Between Analytical Conclusions and Actual Demands

\begin{tabular}{|l|l|l|l|l|l|l|}
\hline customer & a26 & a27 & a28 & a29 & customer demand object \\
\hline 1 & $\begin{array}{l}\text { Actual } \\
\text { demand }\end{array}$ & 5.0 & 2.0 & 2.0 & 3.0 & Communication object, Information object \\
\hline $\begin{array}{l}\text { Analytical } \\
\text { conclusion }\end{array}$ & 4.9 & 3.1 & 2.6 & 3.8 & $\begin{array}{l}\text { Communication object, Business object } \\
\text { Information object }\end{array}$ \\
\hline 2 & $\begin{array}{l}\text { Actual } \\
\text { demand }\end{array}$ & 5.0 & 3.0 & 2.0 & 4.0 & $\begin{array}{l}\text { Communication object, Business object, } \\
\text { Information object }\end{array}$ \\
\hline & $\begin{array}{l}\text { Analytical } \\
\text { conclusion }\end{array}$ & 4.9 & 3. & 2.9 & 3.8 & $\begin{array}{l}\text { Communication object, Business object, } \\
\text { Information object }\end{array}$ \\
\hline
\end{tabular}

\section{Conclusions}

Based on the background of mobile industry, this paper makes mobile customer demand analysis model and proposes ways to capture customer demand knowledge. The method is used to analyze the samples of 122 mobile telecommunication customers. We make a contour model of mobile customer value layer, and screen out $13 \mathrm{key}$ variables of attribute layer. The results of customer demand discrimination reflect its outcome with the correct percentile over $80 \%$. Compared with previous methods of customer clustering analysis, it is more precise and higher in the intelligent level. Furthermore, the conclusion is much more understandable.

\section{References}

1. B. Sharp, and A. Sharp, Loyalty Programs and Their Impact on Repeat-purchase Loyalty Patterns, International Journal of Research in Marketing 14, 473-486 (1997). 
2. R. Boulton, B. Libert, and S.M. Samek, Cracking the Value Code: How Successful Businesses Are Creating Wealth in the New Economy (Harper Collins Publishers Inc., New York, 2000).

3. P.M. Simpson, J.A. Siguaw, and T.L. Baker, Value Creation Supplier Behaviors and Their Impact on Reseller-Perceived Value, Industrial Marketing Management 30, 119-134 (2001).

4. S.S. Srinivasan, R. Andeson, and K. Ponnavolu, Customer Loyalty in E-commerce: An Exploration of Its Antecedents and Consequences, Journal of Retailing 78, 41-50 (2002).

5. A. Inoue, S. Takahashi, K. Nishimatsu, and H. Kawano, Service Demand Analysis Using Multi-Attribute Learning Mechanisms, KIMAS, IEEE, 10, 634-639 (2003).

6. Wan Yinghong, Qian Yuanyuan, and $\mathrm{Li}$ Jiang, The Analysis of Customer Value Dimensions' Difference of the Bank's Interacting Channel, The Second IEEE Conference on Service Systems and Service Management, 193-198 (2005).

7. Burs, M. Jane, and R. B. Woodruff, Value: An Integrative Perspective, Proceedings of the Society for Consumer Psychology, 59-64, (1991). 